\title{
İnovasyonun Çevreci Yüzü ve Türkiye
}

\author{
Yrd. Doç. Dr. Sema YİĞìT \\ Ordu Üniversitesi, İ.I.B.F., İsletme Bölümü, ORDU
}

\begin{abstract}
$\ddot{O Z E T}$
Insanların yaptıkları faaliyetlerinin doğaya olan etkisi artmakta ve doğa bu etkiyi karşılamakta giderek daha çok yetersiz kalmaktadır. Birçok faaliyet gerçekleştiren işletmelerin etkisi ise pek tabi bireylerden daha fazladır. Rekabet gücü elde etmeye yönelik bir işletme faaliyeti olan inovasyon yapmanın ise diğer işletme faaliyetlerden ayrlldı̆̆ önemli bir nokta vardır. Diğer faaliyetler yapllırken önemli olan çevreye olumsuz etki yapmamak iken, inovasyon faaliyetinde önemli olan inovasyon gerçekleştirme sürecinde çevreye duyarl olunmasının yanı sıra diğer faaliyetlerin olumsuz etkilerini azaltacak ve ya elimine edecek bir yönün de olmasıdır. Bu yönü de içinde barındıran inovasyon türü literatürde yeşil/ekolojik/çevresel/sürdürülebilir inovasyon gibi aynı eksendeki farklı tanımlarla yer almaktadır. Çevre yönelimli inovasyon olarak ele alınan bu inovasyon türünü yönlendiren arz, talep ve düzenlemeler olmak üzere üç güç vardır. Bu çalışmanın amacı bu üç güç bağlamında Türkiye'nin değerlendirilmesidir. Yapılan araştırmada Türkiye'nin düzenlemeler konusunda uluslararası desteklerin de yardımıyla oldukça yol kat etmiş olduğu görülürken, talep ve arz için daha fazla çabaya ihtiyaç olduğu düşünülmektedir.
\end{abstract}

Anahtar Kelimeler: Inovasyon, Eko-inovasyon, Yeșil İnovasyon, Sürdürülebilir İnovasyon, Çevresel İnovasyon

JEL Sinıflaması: $013,031, Q 56, Q 57, Q 58$.

\section{Green Side of Innovation and Turkey}

\section{ABSTRACT}

Impact of the activities of people is increasing and nature becomes more insufficient to meet it. Impacts of businesses that perform many activities are inherently more than individuals. Innovation activity which is a business activity to obtain competitiveness is separated from other activities in terms of an important point. While doing other business activities it is important to avoid making negative impact to environment but while performing innovation activity it is also important having aspect to reduce or eliminate the negative impact of other business activities in addition to becoming sensitive to the environment. Type of innovation with this aspect is placed in the literature with different definitions on the same axis like green / ecological / environmental / sustainable innovation. There are three powers as supply, demand and regulations that drive this innovation type as considered environment oriented innovation. The aim of this study is to evaluate Turkey in the context of these three powers. While it has been seen that Turkey get along well about regulations with international supports, it has been considered that further efforts are needed to supply and demand factor.

Key Words: Innovation, Ecological Innovation, Green Innovation, Sustainable Innovation Environmental Innovation.

JEL Classification: $013,031, Q 56, Q 57, Q 58$.

\section{GIRIŞ}

İnovasyon kelimesinin Türkçe karşıllı̆ı olarak literatürde önceleri daha çok yenilik, yenileşim gibi kavramların kullanıldı̆̆ 1 görülmektedir. Ancak günümüzde her yeniliğin tüketici gözünde bir değer taşımadığından hareketle "ticarileştirilebilir yenilik" veya "değer yaratan yenilik" ifadelerinin inovasyon 
kelimesini daha iyi karşıladıkları düşünülmektedir. İnovasyonun hem ticarileştirilebilir olma boyutu hem de değer yaratma boyutu görüldüğü üzere tüketiciye yöneliktir. Yapılan yeniliklerin tüketici gözünde bir değerinin olması ve bu yeniliklerin de ticareti yapılabilir olması gerekmektedir. Böylece inovasyon faaliyetleri amacina ulaşacak, işletmeye kar ve rekabet gücü getirecektir. Günümüzde hem tüketici ihtiyaç ve beklentilerinin değişmesi hem de ulusal ve uluslararası düzenlemeler nedeniyle yeşi1/ekolojik/çevresel/sürdürülebilir inovasyon gibi farklı ancak benzer esaslı tanımlarla anlatılan inovasyonun odağında tüketici ve çevre beraber bulunmaktadır. Türkiye gibi inovasyon faaliyetlerinin önünde birçok engel (araştırma ve geliştirmeye ayrılan bütçenin az olması, nitelikli iş gücü bulma zorluğu, inovasyon faaliyetlerinin sistematik olarak yönetilememesi gibi) olan bir ülkede yapılan inovasyonlarda çevre faktörünün de en az tüketici kadar sürece dâhil edilmesini sağlamak daha zor olmaktadır. Ancak azalan kaynaklar ve insanların yaşam faaliyetlerinin çevreye artan etkisi gerçekleştirilen her faaliyette çevre odaklı olmayı zorunlu kılmıştır. Türkiye'nin çevre odaklı inovasyon faaliyetleri açısından zemininin değerlendirilmesi bu çalışmanın amacını oluşturmaktadır. Bu amaçla önce çevre yönelimli inovasyon ekseninde yer alan farklı kavramlara yer verilmiştir.

\section{II. ÇEVRE YÖNELIMLİ İNOVASYONLAR}

Literatürde bu çalışmada çevre yönelimli inovasyonlar olarak ele alınan dört kavramın birbirinin yerine (özellikle "ekolojik inovasyon" ile "yeşil inovasyon" kavramları) sıklıkla kullanıldığı görülmüştür. Kavramları netleştirmek amacıyla çevre yönelimli inovasyon kavramlarından öncelikle ekolojik inovasyona sonrasında çevresel, sürdürülebilir ve yeşil inovasyona değinilmiştir.

\section{A. Eko-inovasyon}

Eko-inovasyon (ecological/eco-innovation) kavramına ilk olarak Fussler ve James'in 1996 'da yayımladıkları kitapta rastlanmaktadır. Yazarlar ekoinovasyon kavramını yeni ürün ve süreçlerin müşteri ve işletme açısından bir değer sağlarken, çevresel etkileri önemli ölçüde azaltmaları olarak tanımlamışlardır (OECD, 2009: 39-40).

Kemp ve Pearson (2007) ise OECD (2005) tarafindan yapilan inovasyon tanımını baz alarak eko inovasyonun tanımını şöyle yapmışlardır:

Eko-inovasyon örgüt için yeni olan (geliştirme veya benimsemede) ve ilgili alternatifleriyle karşılaştırıldığında yaşam ömürlerinin her aşamasında çevresel riskleri, kirliliği ve kaynak kullanımının (enerji kullanımı dâhil) diğer olumsuz etkilerini azaltan bir ürünün, üretim sürecinin, hizmetin veya yönetim süreçlerinin oluşturulması, benimsenmesi veya kullanılmasıdır (Kemp ve Pearson, 2007: 7).

Aynı çalışmada eko-inovasyon şu şekilde sınıflandırılmıştır (Kemp ve Pearson, 2007: 10-11). 


\section{Çevresel teknolojiler}

- Atık su arıtma teknolojileri de dâhil olmak üzere kirlilik kontrol ve temizleme teknolojileri,

- Daha az kirlilik yaratan ya da emsallerine göre daha etkin kaynak kullanan yeni imalat süreçleri,

- At1k yönetim ekipmanları,

- Çevreyi izleme,

- Yeşil enerji teknolojileri,

- Su temini,

- Gürültü ve titreşim kontrolü.

\section{Çevre için örgütsel inovasyon}

- İkame malların kullanılması, süreçlerin etkinliğinin artırılması veya üretim tesisindeki küçük değişiklikler ile kirliliği önleme programları,

- Malzeme kullanımı ile enerji, su ve atık meseleleri ile ilgili ölçme, raporlama ve sorumlulukları (EMAS ${ }^{1}$ ve ISO 14001 gibi) kapsayan çevre yönetim ve denetim sistemleri,

- Tedarik zincirinin çevreye etkisini en aza indirecek şekilde yönetimi.

\section{Ürün ve hizmet inovasyonu}

- Yeni veya çevresel açıdan geliştirilmiş ürünler,

- Yeşil finansal ürünler (çevreyi koruma amaçla kullanılacak krediler, kiralamalar gibi),

- Katı ve tehlikeli atık yönetimi, su ve atık su yönetimi, çevre danışmanlık, test ve mühendislik hizmetleri gibi çevresel hizmetler,

- Daha az kirlilik oluşturan veya kaynakları daha etkin kullanan hizmetler (ortak araç kullanımı gibi).

\section{Yeşil inovasyon sistemleri}

- Mevcut sistemlere göre daha çevre dostu olan alternatif üretim ve tüketim sistemleri (biyolojik tarım ve yenilenebilir enerji sistemleri gibi).

Eko-inovasyonu yönlendiren unsurların neler olduklarına dair yapılan çalışmalardan biri Rennings'in (2000) çalışmasıdır. Bu çalışmada Şekil 1'de de görüldüğ̈ üzere eko-inovasyonu teknoloji, pazar ve düzenlemelerin yönlendirdiğine yer verilmiştir (Rennings, 2000: 326).

\footnotetext{
${ }^{1}$ EMAS (Eco-Management and Audit Scheme) AB komisyonunun 1995'te ortaya koyduğu işletmelerin ve diğer organizasyonların çevresel performanslarını değerlendirdikleri, rapor ettikleri ve ilerlettikleri bir yönetim aracıdır.
} 


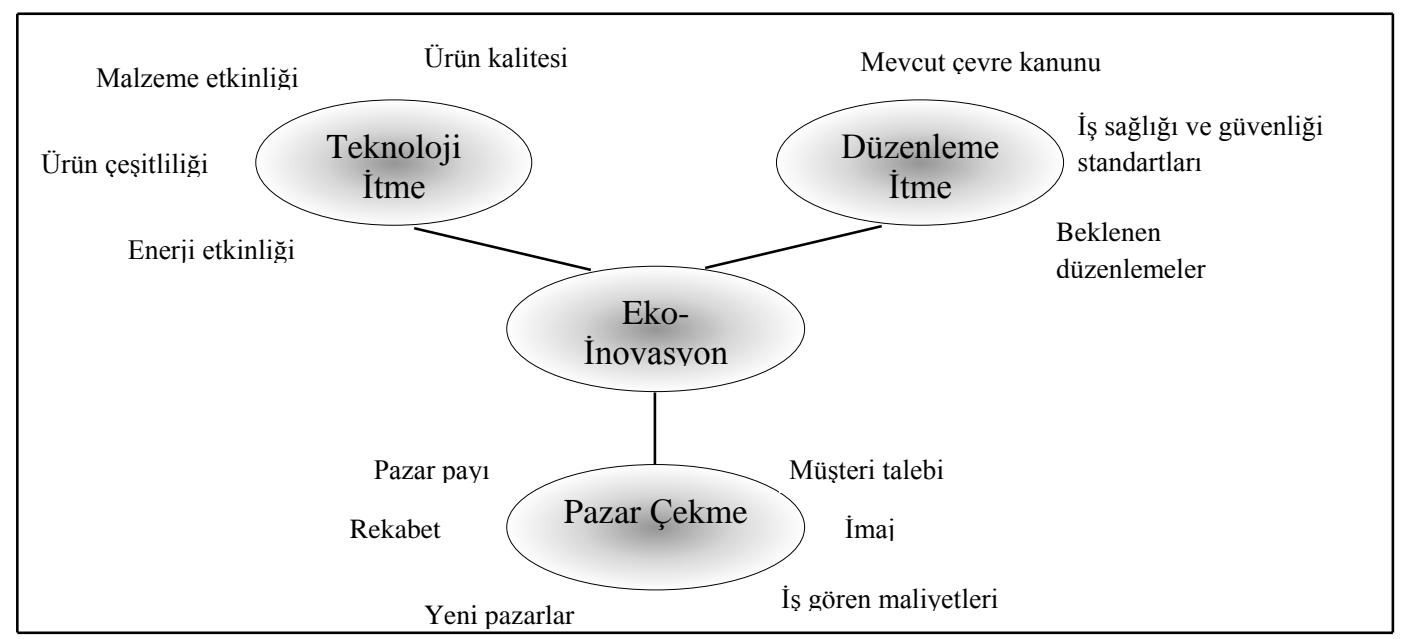

\section{B. Çevresel İnovasyon}

Şekil 1: Eko inovasyonun Belirleyicileri

Çevresel inovasyon (environmental innovation) literatürde genellikle ekoinovasyonla benzer tanımlarla yer almıştır (Rennings, 2000). En geniş anlamıyla çevresel inovasyonlar çevreye yarar sağlayan ve çevresel sürdürebilirliğe katkıda bulunan yeni veya değiştirilmiş süreçleri, uygulamaları, sistemleri ve ürünleri kapsamaktadır (Oltra, 2008: 4).

Rennings ve Ramner (2010) çevresel inovasyonun tanımları incelendiğinde öne çıkan üç özelliği olduğunu ifade etmişlerdir. Birincisi çevresel inovasyonun pazar ve dünya için yeni değil sadece o işletme için yeni olması gerekmektedir. $\mathrm{Bu}$ açıdan çevresel inovasyonlar yeni bir enerji tasarruf teknolojisinin benimsenmesi gibi artımsal bir yenilik olarak görülebilir. İkincisi sonuçları ile ilgilidir. Çevresel inovasyonun yeni ürün ve süreç geliştirilmesi gibi ana öncelikli bir amacı olması önemli değildir. Önemli olan inovasyonun olumlu bir çevresel etki yaratmasıdır. Son olarak alternatifleri ile karşılaştırıldığında ortaya çıkan inovasyonun çevre açısından faydalı (enerji tasarruflu ampuller ve konvansiyonel akkor ampuller gibi) olmasıdır (Rennings ve Ramner, 2010: 5).

Çevresel inovasyonu yönlendiren güçler ise Tablo 1'de yer almaktadır.

Tablo 1: Çevresel İnovasyonu Yönlendiren Güçler

\begin{tabular}{|l|l|}
\hline $\begin{array}{l}\text { Yönetmelikler ve } \\
\text { politikalar }\end{array}$ & $\begin{array}{l}\text { - Çevresel politika araçlarının kullanılması: Ekonomik ve düzenleyici } \\
\text { araçlar, } \\
\text { - Mevcut çevresel düzenlemeler veya beklentiler, } \\
\text { - Düzenleyicilerin kapsamı, esnekliği ve zaman çerçevesi, }\end{array}$ \\
\hline Arz faktörü & $\begin{array}{l}\text { - Maliyet tasarrufları, verimlilik artı̧ları, } \\
\text { - Örgütsel inovasyonlar: çevresel yönetim sistemleri, genişletilmiş üretici } \\
\end{array}$ \\
& $\begin{array}{l}\text { - Arumluluğu, } \\
\text { - Endüstriyel ilişkiler, tedarik zinciri baskısıl, ağ oluşturma faaliyetleri, }\end{array}$ \\
\hline Talep faktörü & $\begin{array}{l}\text { - Çevresel bilinç ve tüketicilerin çevreyle dost ürünlere yönelik algıları, } \\
\text { - Pazar payındaki beklenen artı̧ ve yeni pazar bölümlerine girme imkânı. }\end{array}$ \\
\hline
\end{tabular}

Kaynak: Oltra, 2008: 9 


\section{Sürdürülebilir İnovasyon}

Sürdürülebilirlik kavramı literatürde üzerinde fikir birliğine varılmış bir kavram olamadığından sürdürülebilir inovasyonun (sustainable innovation) tanımını yapmak da zor olmaktadır. Little (2005) sürdürülebilirlik güdümlü inovasyonu sosyal, çevresel veya sürdürülebilirlik meselelerinin yönlendirdiği yeni bir pazar alanının, ürünlerin, hizmetlerin veya süreçlerin oluşturulması şeklinde tanımlamıştır (Little, 2005: 3). Bunun yanı sıra sürdürülebilir inovasyonun tanımı Charter ve Clark (2007) tarafından, sürdürülebilirlik konularının (çevresel, toplumsal, finansal) fikir oluşturma aşamasından Ar-Ge faaliyetlerine ve bu fikri ticarileştirmeye kadar olan işletmenin tüm sistemine entegre edildiği bir süreç olarak tanımlanmıştır (Charter ve Clark, 2007: 9). Tablo 2 sürdürülebilir inovasyonu yönlendiren güçleri göstermektedir.

Tablo 2: Sürdürülebilir İnovasyonu Yönlendiren Güçler

\begin{tabular}{|c|c|}
\hline Arz faktörü & $\begin{array}{l}\text { - Çevresel inovasyonlardan kaynaklanan maliyet tasarrufları, } \\
\text { - Pazar özellikleri ile birlikte işletme büyüklüğü ve pazar yapısı } \\
\text { (Monopolistik yapılarda inovatif olmak için bir teşvik olmadığından } \\
\text { çevresel inovasyonları engelleyebilir), } \\
\text { - Çevresel inovasyonların belirsizliğine karşı tutumlar, } \\
\text { - Yöntem bağımlılıkları (insan kaynakları ve bilgi birikimi gibi mevcut } \\
\text { teknolojik imkânlar başka inovasyonların yapılmasını engelleyebilir), } \\
\text { - İnovasyonun gerçekleştirilmesi için gereken sürenin ayarlanması, }\end{array}$ \\
\hline Talep faktörü & $\begin{array}{l}\text { - Pazar talebi (Devlet, tüketiciler ve firmalar), } \\
\text { - Temiz üretimin gerekliliğine dair toplumsal bilinç, çevreyle dost } \\
\text { ürünlerin tercihi, }\end{array}$ \\
\hline $\begin{array}{l}\text { Kurumsal ve } \\
\text { politik etkiler }\end{array}$ & $\begin{array}{l}\text { - Çevresel politikalar (teşvik tabanlı araçlar veya düzenleyici yaklaşımlar), } \\
\text { - Kurumsal yapı (çevreci gruplar için politik firsatlar, bilgi akışının düzeni, } \\
\text { inovasyon ağlarının varlığı), } \\
\text { - Dünya toplumunun baskısı }\left(\mathrm{CO}_{2} \text { salınımına dair uluslararası anlaşmalar }\right. \\
\text { gibi). }\end{array}$ \\
\hline
\end{tabular}

Kaynak: Horbach, 2005:5

\section{Yeşil İnovasyon}

Leenders ve Chandra (2013) yeşil inovasyonun (green innovation) inovasyon ve çevresel yönetim olmak üzere iki temel kavrama dayandığını ifade etmişler ve yeşil inovasyonu yeni teknolojilerin geliştirilmesini de kapsayan enerji tasarrufuna, kirliğin önlenmesine, atıkların geri dönüşümüne ve eko-verimli tasarımlara odaklanan ürün ve süreç inovasyonu olarak tanımlamışlardır (Leenders ve Chandra, 2013: 204).

Chen vd. (2006) yeşil inovasyonu "Enerji tasarrufu, kirlilik önleme, atık geri dönüşümü, yeşil ürün tasarımını kapsayan yeşil ürün veya süreçlerle ilgili donanımsal veya yazılımsal inovasyonlar veya kurumsal çevre yönetimi” olarak tanımlamışlardır (Chen vd., 2006: 332). Bu tanıma göre yeşil inovasyonun yeşil ürün inovasyonu, yeşil süreç inovasyonu ve yeşil yönetimsel inovasyon olmak üzere üç temel kategoriye ayrıldığını söylemek mümkündür. 


\section{III. ÇEVRE YÖNELIMLİ INOVASYONLAR AÇISINDAN TÜRKIYE}

Çalışmaya dâhil edilen çevre yönelimli inovasyon kavramlarının tanımları bağlamında Türkiye'nin çevre yönelimli inovasyonlar açısından durumunu şu üç faktör altında incelemek doğru olacaktır.

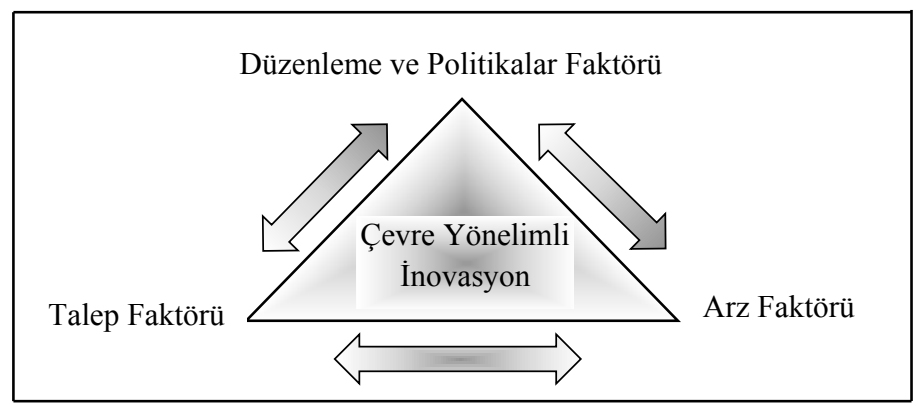

Şekil 2: Çevre Yönelimli İnovasyonu Yönlendiren Güçler

$\mathrm{Bu}$ faktörler arasında karşılıklı bir etkileşim söz konusudur. Çevre yönelimli ürünlere talep oldukça işletmeler buna göre üretim yapacak, yeni karşılaşılan bu durum içinse yeni düzenlemeler gerekecektir. Benzer şekilde uluslararası veya ulusal çabalar vasıtasıyla değişen düzenlemeler tüketicilerin çevre yönelimli inovasyonlara olan farkındalığını artıracak ve bu da yine arzı tetikleyecektir. Başka bir açıdan işletmelerin sürdürülebilirlik ve sosyal sorumluluk anlayışlarının gelişmesi ile faaliyetleri çevre odaklı olacak, bu arz kendine göre bir talep yaratacak, bu da bir düzenleme gerektirecektir.

\section{A. Arz Faktörü}

İşletmelerdeki inovasyon faaliyetlerinin önüne geçen her engel pek tabi çevre yönelimli inovasyonlar için de geçerli olacaktır. Buna rağmen özellikle Türkiye'nin önde gelen firmaları çevreye duyarlılık ve sürdürülebilirlik konusunda birçok çalışma yapmaktadır. Karbon salınımlarının kontrolü ile birlikte miktarının da açıklanması bu çalışmalardan birdir. 2010 yılından beri Karbon Saydamlık Projesi yürütülmekte ve projeye katılan işletme sayısı da giderek artmaktadır. 2010 y1lında 11 işletme raporlama yaparken bu rakam 2011'de 20'ye 2012'de ise 32'ye yükselmiştir (CDPTurkey, 2013).

Türkiye'de çevreci uygulamalara dair patent başvuruları özellikle son altı yılda arttığı görülse de sayısı çok azdır. Türk Patent Enstitüsünden alınan verilere göre ${ }^{2}$ :

\footnotetext{
${ }^{2}$ Buluş başlığında "sürdürülebilir", "çevreci", "ekolojik", "yeşil" kelimeleri geçen başvurulara göre arama yapılmış sadece "çevreci" ve "ekolojik" kelimeleri için uygun başvurular bulunmuştur.
} 


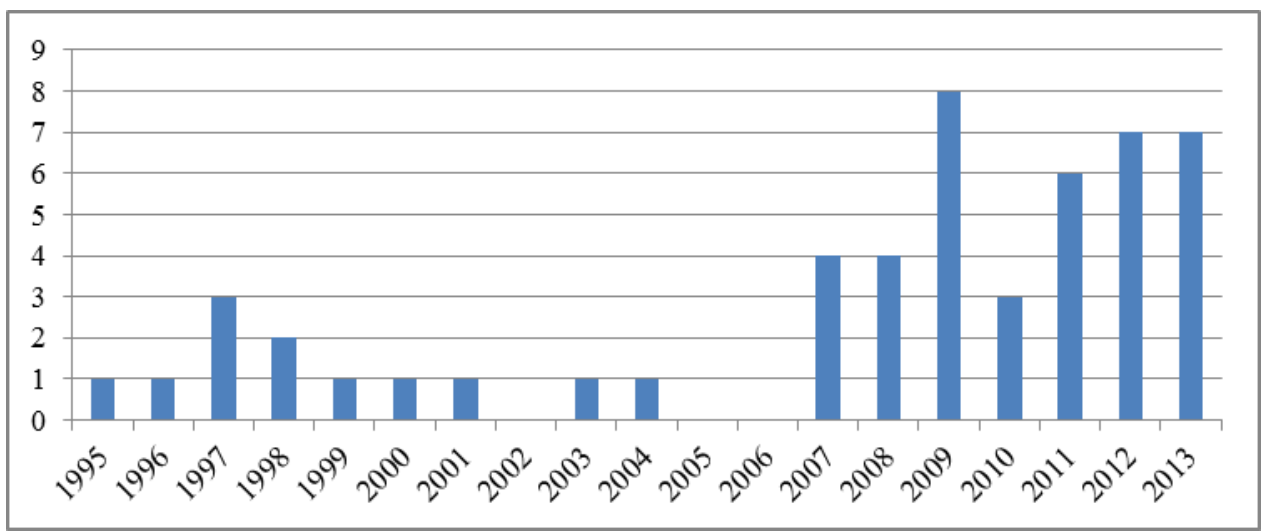

Şekil 3: Buluş Başlığında Çevreci ve Ekolojik Kelimeler İçin Başvurular (Ekim ayı itibariyle)

Türkiye'deki işletmelerin çevre yönelimli inovasyon faaliyetlerinde bulunup bulunmadığını tespit etmek oldukça zor olsa da daha çok inovasyon faaliyetinde bulunan büyük işletmelerin yer aldığı BİST'deki işletmelerin faaliyet raporları incelendiğinde çevre yönelimli inovasyonlar bağlamında aşağıdaki başlıklarda toplanabilecek faaliyetleri yaptıkları görülmüştür (KAP, 2013).

- Enerji tasarruflu ürünlerin ürün gamındaki oranlarının artırılması,

- Elektrik, su ve kâğıt kullanımının kontrolü,

- Atık suların geri dönüştürülmesi,

- Tedarik zincirinin enerji kullanımını azaltacak şekilde yeniden değerlendirilmesi (karayolu yerine demiryolu kullanılması gibi),

- Plastik ambalaj atık miktarının azaltılması,

- Ambalajlarda geri dönüşümlü malzemenin kullanılması,

- Boya ve kimyasal malzeme atık oranını azaltacak teknolojilerin edinilmesi,

- Çalışanlara toplu taşıma hizmeti verilmesi,

- Binalarında 1s1 yalitımı ve mantolama yapılmas1,

- Çalışanlara sürdürülebilirlik eğitimi verilmesi,

- Yeni nesil araçların ve enerji ekipmanlarının kullanılması,

- Güneş enerjisinden yararlanma.

Bunun dışında Büyükkeklik vd.'nin (2010) yaptıkları çalışmada Kayseri'deki 75 işletme üst yöneticisi ile yüz yüze görüşme yöntemi kullanılarak elde ettikleri bilgilere göre, işletmeler tarafindan çevreye yönelik en yüksek düzeyde gerçekleştirilen yenilikler, üretim süreçlerinde oluşan atık miktarlarının azaltılması veya yok edilmesiyle, üretim teknolojilerinde daha az su ve enerji tüketimiyle ve kullanılmış ürünlerden dönüştürülen malzemelerin üretim süreçlerinde girdi olarak kullanılmasıyla ilgilidir. Çalışmalarında da vurguladıkları üzere bu uygulamalar çevre yönelimli inovasyonlardan çok mevcut uygulamalarının çevreye olan olumsuz etkilerini azaltmaya yöneliktir. Çevre 
yönelimli inovasyon yapmanın önündeki engeller ise yeniliklerin ekonomik risklerinin olması, pazardan bu yönde 1srarlı bir talebin gelmemesi ve yeniliklerin gerektireceği maliyetlerin yüksek olması olarak belirtilmiştir.

Dünyada yeşil patent diye nitelendirilen çevreye yararlı ürün ve hizmetlerin patent indeksleri OECD ülkeleri arasında sürekli artmaktadır.

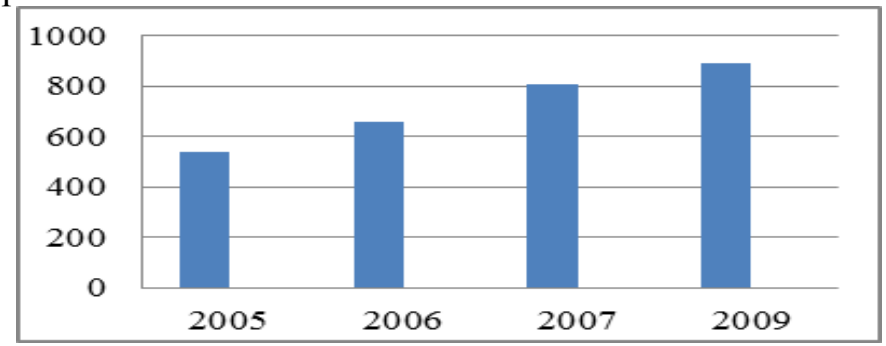

Şekil 4: OECD Ülkelerinin Yeşil Patent İndeksleri (1990=100)

Yine OECD ülkeleri ile Türkiye'nin bazı patent alanlarındaki durumu karşılaştırıldığında Türkiye'deki yeşil patentlerin toplam uluslararası patent sayısı içindeki oranının bir çok değişkende OECD ülkelerinin ortalamasının altında olduğu ve istikrarlı olmadığı görülmektedir (OECD, 2013b).

Şekil 5: Seçilmiş Yeşil Patentlerin Toplam Uluslararası Patent Sayısı (PCT) İçindeki Oranı
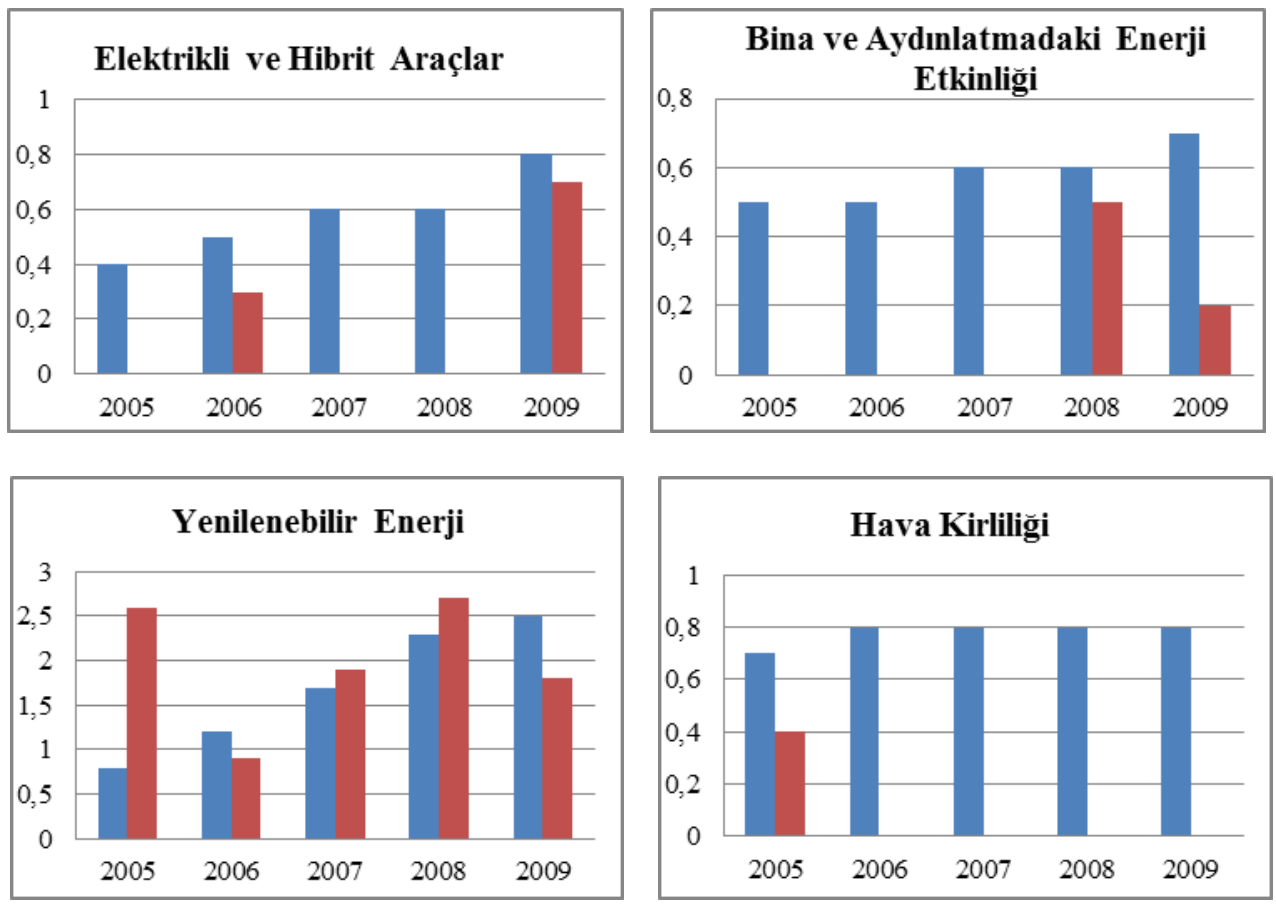

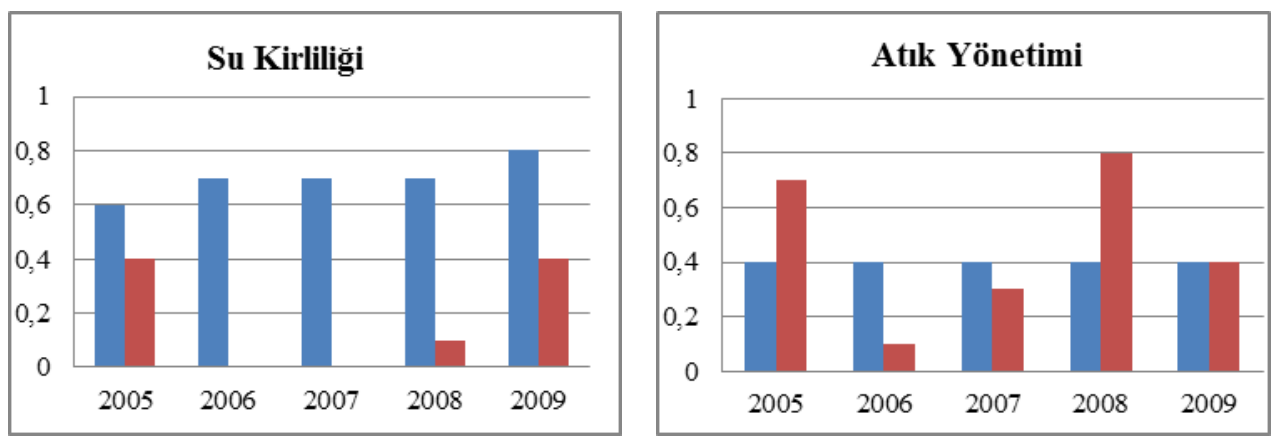

OECD Türkiye

\section{B. Talep Faktörü}

Dünya genelinde olduğu gibi Türkiye'de de tüketicilerin çevreye duyarlılık konusunda git gide daha çok bilinçlendiği söylenebilmektedir. Ancak Türkiye'de tüketicilerin çevre dostu ürünlere olan bakışını öğrenmeye yönelik çok fazla araştırma yapılmamıştır. Yapılan az sayıdaki çalışmalardan biri Tüketici ve Çevre Eğitim Vakfı tarafından 2010'da yapılan İşletmelerin Çevre Yönetimi ve Duyarlılığının Tüketici Davranışlarına Etkisi Araştırmasıdır. 26 ili ve 1536 kişiyi kapsayan bu çalışmada katılımcıların \%28,3'ü daha önce bilinçli olarak çevre dostu ürün satın almış, \%71,7'si almamıştır. Satın alanların \%83'ü üründen memnun kalırken bunların \%96,3'ü satın almaya devam edeceklerini ifade etmişlerdir (TÜKCEV, 2012).

Sürdürülebilirlik Akademisi tarafindan 2011 y1lında ilk defa Yeşil Tüketim Araştırması yapılmıştır. 15 ilde 1487 kişi ile yapılmış çalışmada satın aldığ1 ürünlerin yeşil/çevre dostu olması gerektiğini düşünenlerin oranı \%71 olmasına rağmen sıklıkla yeşil/çevre dostu ürünleri satın alanların oranı sadece $\% 19$ 'dur. Yeşil/çevre dostu ürünlerin satın alınmama nedenleri arasında ilk sırayı \%57 ile yüksek fiyat almıştır. Bunu ürünlerin çeşitliliğinin sınırlı olması ve ürün bilgilerinin güven vermemesi izlemiştir (Sürdürülebilirlik Akademisi, 2011).

Aynı çalışma 2012'de yine 15 ilde ve 1334 kişinin katılımıyla tekrarlanmıştır. Bu çalışmada tüketicilerin yüzde 13'ünün her zaman yeşil ürün kullandığ1 tespit edilmiştir. Yine bu tür ürünlerin fiyatlarının yüksek olması satın almanın önündeki en büyük engeldir (ÇEVKO, 2013).

Türkiye'de daha önce yer verilen çalışmalar kadar geniş kapsamlı olmasa da çevreci ürünlere yönelik talebin yapısını inceleyen başka çalışmalar da mevcuttur. Kardeş (2011) tarafından çok büyük bir kısmı öğrenci olan 186 kişinin katılımıyla yaptıkları çalışmada çevre dostu markayı tercih etmeyi pozitif yönde etkileyen en güçlü etkenin tüketicinin kendisini çevreci bir kişilik olarak tanımlaması olduğu ortaya çıkmıştır. Katılımcıların çevre dostu markalara yönelik olumlu bir tutum gösterdikleri ve ürün satın almada çevre faktörü kriterini tecrübe, kalite ve fiyattan sonra dikkate aldıkları ortaya çıkan diğer bir önemli sonuçtur. 
Yeniçeri'nin (2009) Aksaray Üniversitesi'nde 450 öğrenci üzerinde anket yöntemi kullanarak yaptığı çalışmada, çevreye duyarlı satın alma davranışı ve çevre bilinci bakımından en yüksek ortalamaya sahip olanların toplam cevaplayıcılara oranının \%38,6 olduğu görülmüştür. Ayrıca çevre bilinci yüksek ve çevreye duyarlı satın alma davranışı gösteren tüketicilerin daha çok öğrenim düzeyi yüksek, nispeten yüksek gelirli kadınlardan oluştuğu tespit edilmiştir.

Aracıoğlu ve Tatlıdil (2009) İzmir ilindeki 18 yaş üstü 360 kişiyi kapsayan çalışmalarında cevaplayıcıların \%83'ü, çevreyi daha az kirletecek bir ürün için fazladan ödeme yapabileceğini ifade etmiştir. Çevresel nedenlerden ötürü kullandığı ürünleri değiştirebileceğini söyleyen cevaplayıcıların oranı \%84 iken çevreye zarar veren bir ürün satın almayacağını ifade edenlerin oranı $\% 67$ olmuştur.

Alnıaçık (2010) Marmara Bölgesi’nde yerleşik yedi ayrı üniversite okuyan 1254 öğrenciden anket yöntemi kullanarak elde ettiği verilere göre belirli bir marka ürünün gerçekten çevre dostu olduğuna dair yeterli kanıt sunulsa, o marka ürününe sadık bir tüketici olurum diyenlerin oranı \%84,9'dur. Firmaların çevreyi daha iyi koruyabilmeleri için satın aldığı mal ve hizmetlere daha fazla fiyat ödeyebileceğini ifade edenlerin oranı ise $\% 73,5^{\prime}$ tir.

\section{Yasal Düzenlemeler ve Teşvikler}

Türkiye'de çevre yönelimli inovasyonlara dair doğrudan bir düzenleme olmasa da çeşitli kanun ve düzenlemelerin dolaylı etkileri mevcuttur. Bunları iki kısımda incelemek doğru olacaktır.

Ulusal Düzenlemeler ve Teşvikler: Çevre ile ilgili ana düzenleme dayanağ çevre kanunudur. Kanunda daha çok atık yönetimi, su kirliği ve hava kirliliği ile ilgili hükümler yer almaktadır. Bunların dışında gürültü ve titreşime, toprak kirliliğine, arıtma ve bertaraf etme faaliyetlerine, tehlikeli kimyasalların durumuna ve biyolojik çeşitliliğin ve ekosistemin korunmasına ilişkin hükümler kanunun sanayi sektörüne etki ettiği alanlardır. Kanun bunların dışında işletmelere çevresel etki değerlendirmesi yapmak, bildirim ve bilgi verme yükümlüğü yerine getirmek ve çevre yönetim birimi kurma ve çevre görevlisi bulundurmak gibi sorumluluklar da yüklemiştir (Çevre ve Şehircilik Bakanlığı, 2006).

Enerjinin etkin kullanılması, israfinın önlenmesi, enerji maliyetlerinin ekonomi üzerindeki yükünün hafifletilmesi ve çevrenin korunması için enerji kaynaklarının ve enerjinin kullanımında verimliliğin artırılmasını amaçlayan Enerji Verimliliği Kanunu da işletmelere ve kurumlara bilgi verme, enerji yöneticisi görevlendirme ve asgari verim sınırının altında kalan ürünleri satmama gibi yükümlülükler getirmiştir. Ayrıca endüstriyel işletmelerde Verimlilik Artırıcı Projeler (VAP) desteklenmektedir (Enerji ve Tabii Kaynaklar Bakanlığı, 2007).

İklim Değişikliği Ulusal Eylem Planı ve Enerji Verimliliği Strateji Belgesi (2011-2023) dâhilinde sanayi sektöründe enerji verimliliğinin arttırılması, 2023 yılına kadar sanayi sektöründe üretilen GSYİH başına eşdeğer $\mathrm{CO}^{2}$ yoğunluğunun azaltılması ve iklim değişikliği ile mücadeleye yönelik olarak 
sanayi sektörü kapasitesinin güçlendirilmesi amaçlanmıştır (Çevre ve Şehircilik Bakanlığı, 2011).

Türkiye Sanayi Strateji Belgesinde (2011-2014) çevre, yatay sanayi politikası alanlarından biri olarak belirtilmekte ve Türk Sanayisi için sürdürülebilir kalkınma ilkeleri çerçevesinde çevre politikalarının uygulanması sanayi stratejisinin önemli bir parçası olarak görülmektedir (Sanayi ve Ticaret Bakanllı̆ 1 , 2010).

10. Kalkınma Planında (2014-2018) sürdürülebilir kalkınma hedeflerine ulaşmak için küresel ölçekte başlayan yeni büyüme modeli arayışlarıyla birlikte "yeşil büyüme" kavramının önem kazandığı belirtilmektedir. Bu kavram çerçevesinde, üretim sektörlerinde temiz üretim ve eko-verimlilik ile hem çevrenin korunması hem de rekabetçiliğin artırılması mümkün görülmektedir. İmalat sanayisine yönelik politikaların hemen hepsinde yenilik ve sürdürülebilirlik kavramlarına yer verilmiş olup birçok sektörün sürdürülebilir çevre bağlamında yaptıkları çalışmaların da destekleneceği yer almaktadır (Kalkınma Bakanlığı, 2013).

Türkiye'deki diğer kuruluşların da çevre yönelimli inovasyona dair bazı teşvikleri olduğu görülmektedir. Bunların en önemlisi Türkiye'deki araştırma ve geliştirme projelerine en çok maddi destek sağlayan resmi kurum olan TÜBİTAK'tır. 2013-2017 stratejik planında kurumun görevleri arasında insan ve çevre sağlığına katkı sağlamaya dönük stratejik alanlarda araştırmalar yapmak ve yaptırmak da sayılmaktadır. Kurumun çevre kirliğini önleyecek veya çevreyi temizleyecek ürünlere, hibrit ve elektrikli araçlara yönelik geliştirilen ürünlere ve sistemlere verdiği destekler bu kapsamdadır. Bunun dışında Türkiye Teknoloji Geliştirme Vakfı ve bazı kalkınma ajansları (İzmir, Ankara, Doğu Marmara Kalkınma Ajansları gibi) çevre teknolojileri (temiz üretim/ sürdürülebilir üretim) ve enerji verimliliği alanlarında sanayi kuruluşları tarafından gerçekleştirilen uygulama projelerine finansman desteği sunmaktadırlar. Ayrıca Enerji ve Tabii Kaynaklar Bakanlığı ve Türkiye Sürdürülebilir Enerji Finansman Programı (TurSEFF ) enerji verimliliği ve yenilenebilir enerji konularında maddi destek sağlamaktadır.

Uluslararası Düzenlemeler ve Teşvikler: 1992 yılında Birleşmiş Milletler (BM) Çevre ve Kalkınma Konferansı'nda imzaya açılan ve 1994'te yürürlüğe giren BM İklim Değişikliği Çerçeve Sözleşmesi insan kaynaklı faaliyetlerin neden olduğu küresel ısınmanın iklim üzerindeki etkilerine karşı uluslararası alanda atılan ilk ve en önemli adım olarak görülmektedir. Türkiye'nin 2004 yılında katıldığı sözleşme ile birlikte Türkiye için sera gazı salınımlarını sınırlandırmak, sera gazı yutaklarını korumak ve geliştirmek, ayrıca, iklim değişikliğini önlemek için aldıkları önlemleri ve izlenilen politikaları bildirmek ve mevcut sera gazı salınımlarını ve salınımlarla ilgili verileri iletmekle yükümlüğü getirilmiştir. Daha sonra özellikle gelişmiş ülkelerin kararlı ve bağlayıcı yükümlülükler almaları için söz konusu sözleşmeye taraf ülkeler 1997 de Kyoto protokolünü kabul etmişlerdir. Türkiye 2009'dan bu yana protokole taraftır (Dışişleri Bakanlığı, 2013). 
Avrupa Birliği'nin Rekabet Edebilirlik ve Yenilik Çerçeve Programının (CIP) birinci bileşeni olan Girişimcilik ve Yenilik Programının (EIP) inovasyonu destekleme faaliyeti içerisinde eko inovasyon ve Eko-İnovasyon Eylem Planının (EcoAP) uygulanması da yer almaktadır. Bu program dâhilinde ilk kez sunulan teknik olarak kanıtlanmış ancak birtakım riskler nedeniyle piyasaya erişimi için teşvik ve desteğe ihtiyaç duyan projelere 2008 yılından beri finansal destek verilmektedir (Bilim, Sanayi ve Teknoloji Bakanlığı, 2013).

\section{TARTIŞMA ve SONUÇ}

Dünya kaynaklarının önemli ölçüde azalması sürdürülebilirlik konusuna olan dikkatleri artırmıştır. İşletmelerin doğaya etkisi bireylerden daha fazla olduğu için sürdürülebilirliği de bireylerden daha fazla dikkate almak zorundadırlar. Dünyadaki birçok büyük işletme bu doğrultuda faaliyetlerinde daha çevreci olmaya özen göstermekte böylece hem sürdürülebilirliğe katk1 yapmakta hem de marka değerlerini artırmaktadır. Interbrand ve Deloitte danışmanlık kuruluşlarının 2013 yılında en değerli markalar sıralamasındaki ilk 50 markanın 33 tanesi (\%66'sı) aynı zamanda En Yeşil 50 marka arasında da yerini almıştır. Diğer 17 markanın pek çoğu hizmet sektöründe faaliyet gösteren (medya, yazılım, finans gibi) işletmelerin markalarıdır (Interbrand, 2013). Bu sonuç doğaya hizmet sağlayıcılardan daha fazla etkisi olan imalat işletmelerinin, faaliyetlerinde çevreye duyarlı davranmakta olduklarını göstermektedir.

Birçok açıdan önemli bir işletme faaliyeti olan inovasyon faaliyetlerinin çevre yönelimli olanları literatürde ekolojik/çevresel/sürdürülebilir veya yeşil inovasyon olarak nitelendirilen tanımlarla yerini almıştır. $\mathrm{Bu}$ kavramlar incelendiğinde birbirlerinin yerine sıklıkla kullanıldıkları ve birçok ortak paydalarının oldukları görülmüştür ve bu çalışmada hepsini kapsayan bir tanım olması nedeniyle çevre yönelimli inovasyonlar olarak tanımlanmışlardır. Çevre yönelimli inovasyonları yönlendiren üç faktör tespit edilmiştir. Bunlar düzenleme ve politikalar, arz faktörü ve talep faktörleridir.

$\mathrm{Bu}$ üç faktör açısından Türkiye'nin durumu değerlendirildiğinde düzenleme ve politikalar açısından oldukça iyi bir ilerleme kaydetmiş olunduğu görülmektedir. $\mathrm{Bu}$ etkide $\mathrm{AB}$ sürecinin ve taraf olunan uluslararası anlaşmaların da rolü büyüktür. Verilen teşvikler ise azımsanmayacak ölçüdedir. Çeşitli kanunların ve düzenlemelerin farklı açılardan çevre yönelimli inovasyon faaliyetlerine etkide bulundukları görülmektedir.

Talep faktörü incelendiğinde bu alanda geniş kapsamlı çalışmaların yapılmamış olduğu göze çarpmasına rağmen mevcut çalışmalar incelendiğinde dünyanın genelinde olduğu gibi Türkiye'de de çevre konusundaki bilincin giderek arttığ 1 görülmüştür. Ancak satın almada hala ürün fiyatı, geçmiş deneyimler ve çeşit sayısı ön plandadır.

Arz faktörü açısında çevre yönelimli inovasyonlar incelendiğinde durumun çok da iç açıcı olmadığı görülmektedir. İnovasyon yapmanın önünde bir sürü engel olan Türkiye'de (maliyet ve zaman kısıtları, nitelikli işgücü eksikliği, teknik bilgi eksikliği gibi) aynı engeller ve daha fazlası çevre yönelimli inovasyonlar için de geçerlidir. Ancak söz konusu inovasyonlar açısından arzın 
artmasının daha çok düzenleme ve politika faktörünün itme etkisi ile olacağ1 düşünülmektedir. Zira 16 OECD ülkesinde yapılan bir çalışmada firmaları çevresel inovasyon yapma konusunda en çok motive eden unsurun düzenlemeler olduğu görülmüştür. Talep faktörünün de yine oldukça etkili olduğu tespit edilmiştir. Ancak araştırmada beklenmeyen bir sonuç olarak kısa dönemli mali teşvikler en az motive edici unsur olarak görülmüsstür (OECD, 2013a: 16).

İşletmelerin nihai hedefi rekabet gücü elde etmek ve bunu sürdürülebilir kılmaktır. Müşteri gözünde değeri olan bir yenilik yapmak bu hedefe ulaşmayı pek tabi sağlayabilir. Ancak hem müşteri hem çevre açısından değeri olan inovasyonlar yapmak zorunluluğu artık kaçınılmazdır. İşletmelerin, tüketicilerin ve devletin bu durumun farkında olarak çevre bilinci doğrultusunda hareket etmeleri gerekmektedir. Eskiden sıkça kullanılan birçok kavramın başına günümüzde "sürdürülebilir" kelimesinin eklenmesi (sürdürülebilir rekabet gücü, sürdürülebilir büyüme, sürdürülebilir kalkınma, sürdürülebilir enerji gibi) çevre konusundaki bilincin artmasının göstergesidir. Ayrıca OECD’nin Yeşil Büyüme Raporlarında çevre yönelimli inovasyonların sadece çevresel değişikliklere etkili ve verimli çözümler bulma potansiyeli taşımayıp aynı zamanda işletmelerin rekabet gücünü de çeşitli yollarla artırdığından bahsedilmektedir. Bu yollardan ilki verimliliği ve enerji etkinliğini artırarak maliyetleri düşürmesidir. İkincisi çevre yönelimli ürün veya hizmet pazarının hem OECD ülkelerinde hem de diğer ülkelerde giderek büyümesidir. Son olarak ise çevre yönelimli inovasyonların yeni iş fırsatlarının oluşmasını sağlama ihtimallerinin olmasıdır (OECD, 2013a: 15-16).

\section{KAYNAKÇA}

ALNIAÇIK, Ümit (2010), "Çevreci Yönelim, Çevre Dostu Davranış ve Demografik Özellikler: Üniversite Öğrencileri Üzerinde Bir Araştırma”, Sosyal ve Ekonomik Araştırmalar Dergisi, 14(20),507-532.

ARACIOĞLU, Burcu ve Rezan TATLIDİL (2009), “Tüketicilerin Satın Alma Davranışında Çevre Bilincinin Etkileri”, Ege Akademik Bakış Dergisi, 9(2), 435-461.

BİLIM, SANAYİ VE TEKNOLOJİ BAKANLIĞI (2013), Rekabet Edebilirlik ve Yenilik Çerçeve $\begin{array}{lllll}\text { Programı - Girişimcilik ve Programı } & \end{array}$ https://www.sanayi.gov.tr/Files/Documents/2013-eko-inovasyon-turkce514201335746PM.pdf (01.09.013).

BÜYÜKKEKLIK, Arzum, Murat TOKSARI ve Hasan BÜLBÜL (2010), "Çevresel Duyarlılık ve Yenilikçilik Üzerine Bir Araştırma”, Süleyman Demirel Üniversitesi İktisadi ve İdari Bilimler Fakültesi Dergisi,15(3),373-393.

CDP- Carbon Disclosure Project, CDP Türkiye, http://cdpturkey.sabanciuniv.edu/tr/about (02.10.2013).

CHARTER, Martin ve Tom CLARK (2007), "Sustainable Innovation: Key Conclusions from Sustainable Innovation Conferences 2003-2006 Organized by the Centre for Sustainable Design", The Centre for Sustainable Design, http://www.cfsd.org.uk/Sustainable\%20Innovation/Sustainable_Innovation_report.pdf (26.08.2013).

CHEN, Yu-Shan, LAI, Shyh-Bao ve Chao-Tung WEN (2006). "The Influence of Green Innovation Performance on Corporate Advantage in Taiwan", Journal of Business Ethics, 67(4), 331339. 
ÇEVRE VE ŞEHIRCILIK BAKANLIĞI (2006), Çevre Kanunu, http://www.csb.gov.tr/turkce/index.php?Sayfa=kanunliste, (08.09.2013).

ÇEVRE VE ŞEHİRCILİK BAKANLIĞI (Temmuz 2011), Türkiye Cumhuriyeti İklim Değişikliği Ulusal Eylem Planı 2011-2023,

http://web.ogm.gov.tr/diger/iklim/Dokumanlar/RAPORLAR/\%C4\%B0DEP.pdf, (01.09.2013).

ÇEVKO-Çevre Koruma ve Ambalaj Atıklara Değerlendirme Vakfı, http://www.cevko.org.tr/cevko/Ic-Sayfa/Cevko/Haberler/yesil_tuketim_2012.aspx (02.09.2013).

DIŞİ̧LERİ BAKANLIĞI (2013), Uluslararası Çevre Konuları, http://www.mfa.gov.tr/uluslararasi-cevre-konulari.tr.mfa (10.09.2013).

ENERJI VE TABIİ KAYNAKLAR BAKANLIĞI, Enerji Verimliliği Kanunu, http://www.enerji.gov.tr/mevzuat/5627/5627_Sayili_Enerji_Verimliligi_Kanunu.pdf (01.10.2013).

FUSSLER, Claude ve Peter JAMES (1996), Driving Eco-innovation: A Breakthrough Discipline for Innovation and Sustainability, London: Pitman Publishing.

HORBACH, Jens (2005), Indicator Systems for Sustainable Innovation, New York: Physica- Verlag Heidelberg.

INTERBRAND (2013), Best Global Green Brands 2013,

http://www.interbrand.com/en/best-global-brands/Best-Global-Green-Brands/2013/Best-GlobalGreen-Brands-2013.aspx\# (24.10.2013).

KALKINMA BAKANLIĞI (Temmuz 2013), "Onuncu Kalkınma Planı (2014-2018)" http://www.dpt.gov.tr/DocObjects/view/15089/Onuncu_Kalk\%C4\%B1nma_Plan\%C4\%B 1.pdf $(01.10 .2013)$.

KARDEŞ, İlke (2011), "Markaların Çevre Dostu Uygulamalarının Tüketicinin Marka Tercihi Üzerindeki Etkisi”, Ege Akademik Bakış Dergisi,11(1), 165 -177.

KAP -Kamuyu Aydınlatma Platformu (2013) , "Şirket Raporları", http://www.kap.gov.tr/ (03.09.2013).

KEMP, René ve Peter PEARSON (2007), "Measuring Eco-Innovation", Final Report of MEI Project, http://www.oecd.org/env/consumption innovation/43960830.pdf (05.06.2013).

LEENDERS, Mark A.A.M. ve Yanto CHANDRA (2013), "Antecedents and Consequences of Green Innovation in the Wine Industry: The Role of Channel Structure", Technology Analysis \& Strategic Management, 25(2):203-218.

LITTLE, Arthur D. "How Leading Companies are Using Sustainability-Driven Innovation to Win Tomorrow's Customers", Innovation High Ground Report, http://www.adlittleus.com/uploads/tx extthoughtleadership/ADL Innovation High Ground report 03.pdf (01.10.2013).

RENNINGS, Klaus (2000), "Redefining Innovation-Eco-Innovation Research and the Contribution from Ecological Economics”, Ecological Economics,32, 319-32.

RENNINGS, Klaus ve Christian RAMMER (2010), "The Impact of Regulation-Driven Environmental Innovation on Innovation Success and Firm Performance", Discussion Paper No. 10-065, ftp://ftp.zew.de/pub/zew-docs/dp/dp10065.pdf (10.01.2013).

OECD (2005), "Guidelines For Collecting And Interpreting Innovation Data, 3rd Edition", A joint publication of OECD and Eurostat,

http://www.tubitak.gov.tr/tubitak_content_files/BTYPD/kilavuzlar/Oslo_Manual_Third_E dition.pdf (03.03.2013).

OECD (2009), "Eco-Innovation in Industry Enabling Green Growth", OECD Publications,http://books.google.com.tr/books?id=z8UwVYm004YC\&printsec=frontcove

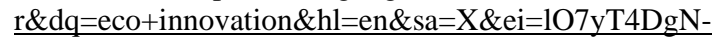
j44QSNysDJCQ\&redir_esc=y\#v=onepage \&q=eco\%20innovation\&f=false $(08 / 08 / 2013)$.

OECD (Şubat 2013a), "Why New Business Models Matter for Green Growth", OECD Green Growth Papers,

http://www.verhaert.com/homepage/wp-content/uploads/2013/03/OECD Whynewbusinessmodelsmatterforgreengrowth.pdf $(01.09 .2013)$.

OECD (2013b), "Yeşil Büyüme İndeksleri", http://stats.oecd.org/Index.aspx?DataSetCode=GREEN_GROWTH 
OLTRA, Vanessa (Aralı, 2008), "Environmental Innovation and Industrial Dynamics: The Contributions of Evolutionary Economics", DIME Working Papers, http://www.dimeeu.org/files/active/0/DIME_WP_n7_oltra.pdf (01.09.2013).

SANAYİ VE TİCARET BAKANLIĞI (Aralık,2010), "Türkiye Sanayi Strateji Belgesi”, http://www.sanayi.gov.tr/Files/Documents/sanayi_stratejisi_belgesi_2011_2014.pdf, (06.08.2013).

SÜRDÜRÜLEBİLIRLIKK AKADEMISİ (2012), "Yeşil Tüketim Araştırması"

http://www.surdurulebilirlikakademisi.com/UyelereOzel/YesilTuketimArastirmasi2011WebIcin.pdf (05.09.2013).

TurSEFF- Türkiye Sürdürülebilir Enerji Finansman Programı, http://www.turseff.org/ (28.09.2013).

TÜBİTAK-Türkiye Bilimsel ve Teknolojik Araştırma Kurumu, http://www.tubitak.gov.tr/ (25.09.2013).

TÜKCEV (2012), "İşletmelerin Çevre Yönetimi ve Duyarlılığının Tüketici Davranışlarına Etkisi”, http://www.tukcev.org.tr/assets/publish/tuketici_arastirmalari/Isletmelerin\%20Tuketici\%2 0Davr_\%20Etkisi_Aras_rapor_3.pdf (02.10.2013).

YENIÇERİ, Tülay (2009), "Tüketicilerin Çevre Bilinci ve Çevreye Duyarlı Satın alma Davranışlarına Yönelik Bir Pilot Araştırma”, Sosyal ve Ekonomik Araştırmalar Dergisi, 11(17),311-326. 